\title{
How Leprosy was regarded by the African Natives before Europeans came
}

Sister M. Thecla Stinnesbeck.

$7 \mathrm{HE}$ lepers living at the leper settlement at Ndanda, Tanganyika Territory, are mostly Wannvera, Wamakua, Wajao and Wamakonde. They give the following information.

Amongst the natives leprosy was always regarded as an infectious and incurable disease, and they carefully avoided coming in touch with a leper. A leper was forced to take his food separately. Young people, suffering from nodular leprosy, were forbidden to marry. If the disease manifested itself after marriage in young people, they were divorced, but elder married people were allowed to live together. Children, although it was known that they would be infected if they were not taken away from their parents, were not removed from their mothers. The excuse given was that nobody but the mother can rear her own child.

Advanced cases were segregated. The relations built a hut apart from the rest, and forbade the sick person to leave it. Some tribes were cruel and fastened the door outside, leaving the leper without food or drink, to starve to 
death. Others were less cruel, they brought food and drink until the leper himself refused to take anything. But the relations never entered a leper's hut. These were always locked from the outside, and as soon as they no longer heard any obvious sign of life inside, they ceased visiting the leper and left the corpse to rot with the hut. They never willingly burnt down the said hut. The relations themselves removed elsewhere. This is being done up to the present day where no Europeans reside.

Native treatment of leprosy consists of rubbing into the skin the juice of a plant that scales the whole skin. Besides that they give the patient a drastic emetic and purgative. I saw one case of nerve leprosy whose raised patches became flat

this is no cure for nodular leprosy, but is a temporary cure for nerve cases which holds good for about a year.

It is difficult to estimate the correct number of lepers. We have 1,600 registered, living mostly between the Ruvuma and the Mbemkuru. There are 3-3.5 per cent. amongst the children attending our mission schools. The percentage of lepers who confess to having a member of the family suffering from leprosy is 33.5 per cent. In reality, I think, the number is much higher, hecause many cases are not recognised by them to be leprosy. Neither are the following figures very reliable concerning the length of time from the outbreak of leprosy until the patients came for treatment :-

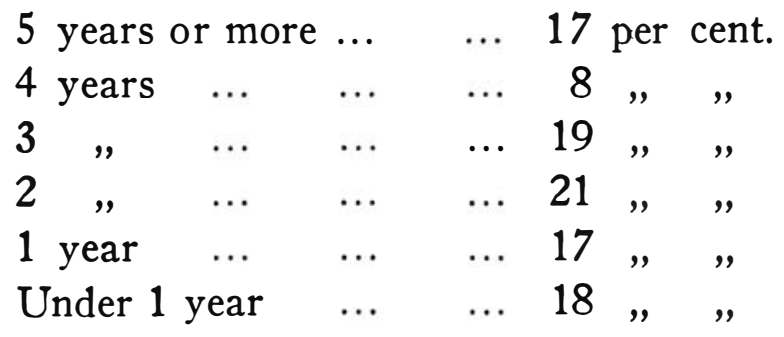

Many of the natives are afraid to say how long they have been suffering, even if they remember the time that has elapsed. 
IEPROS' IOSPTAL, NIANIA, TAN(ANYIKE TLRRITR'

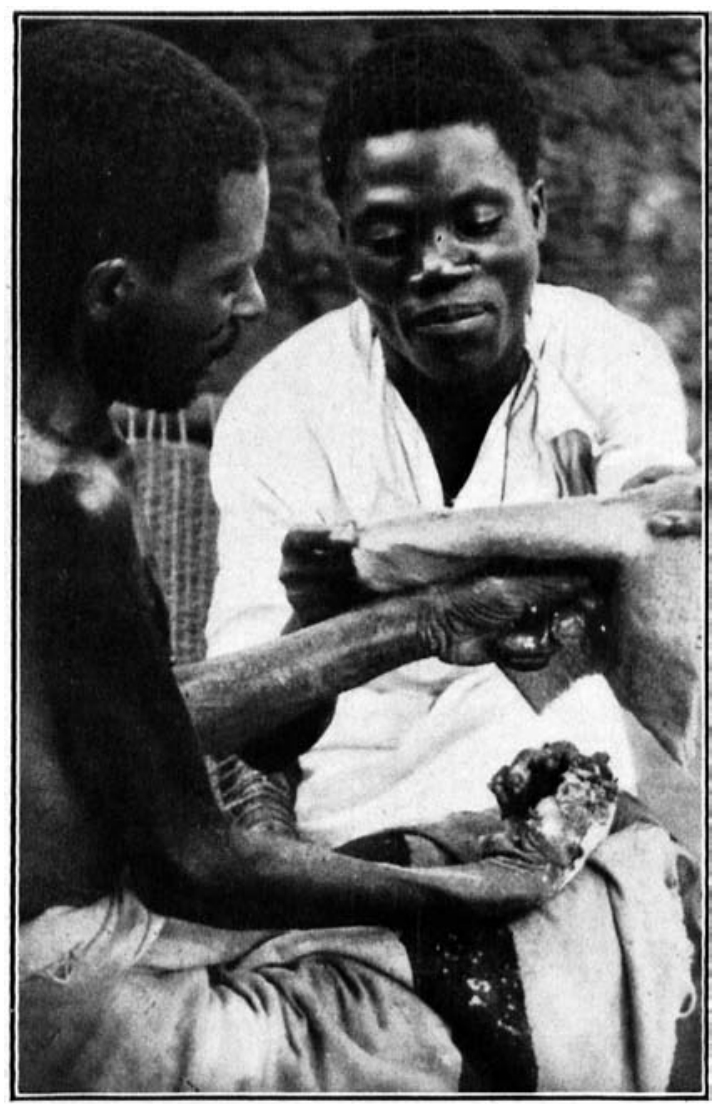

Dressing; Lilchating Hands.

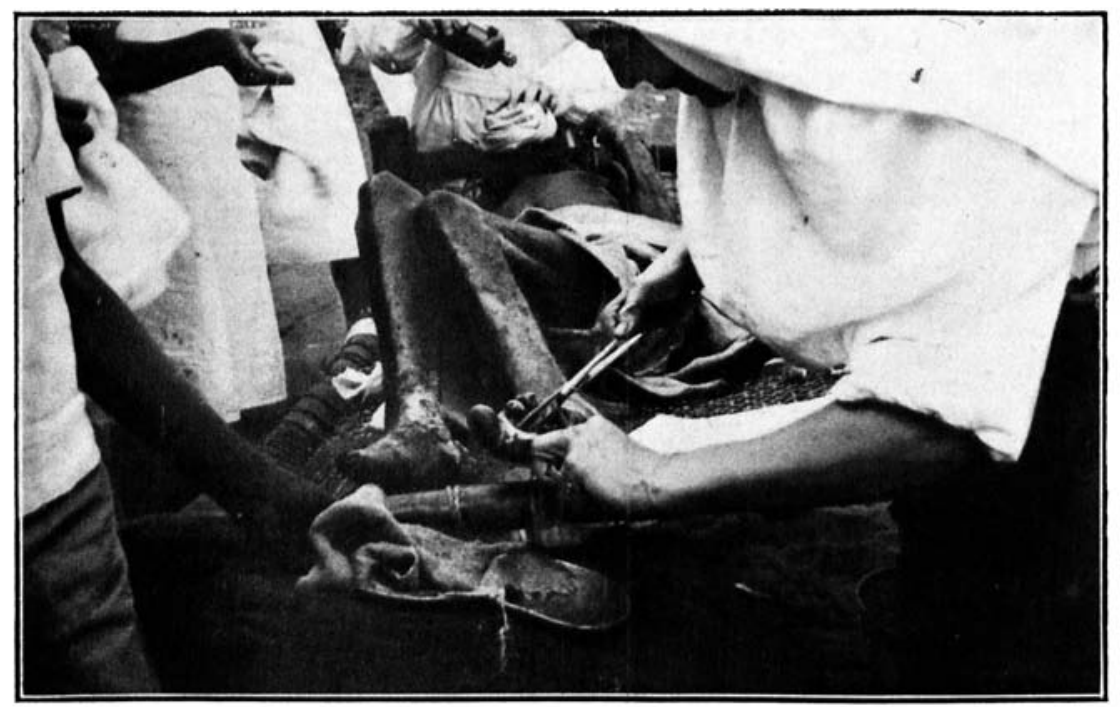

OpleRATING on Gangikenolis froOt. 
KUYU IEPLR COIONY, IIUI.I.

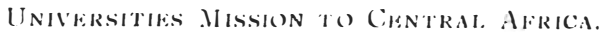

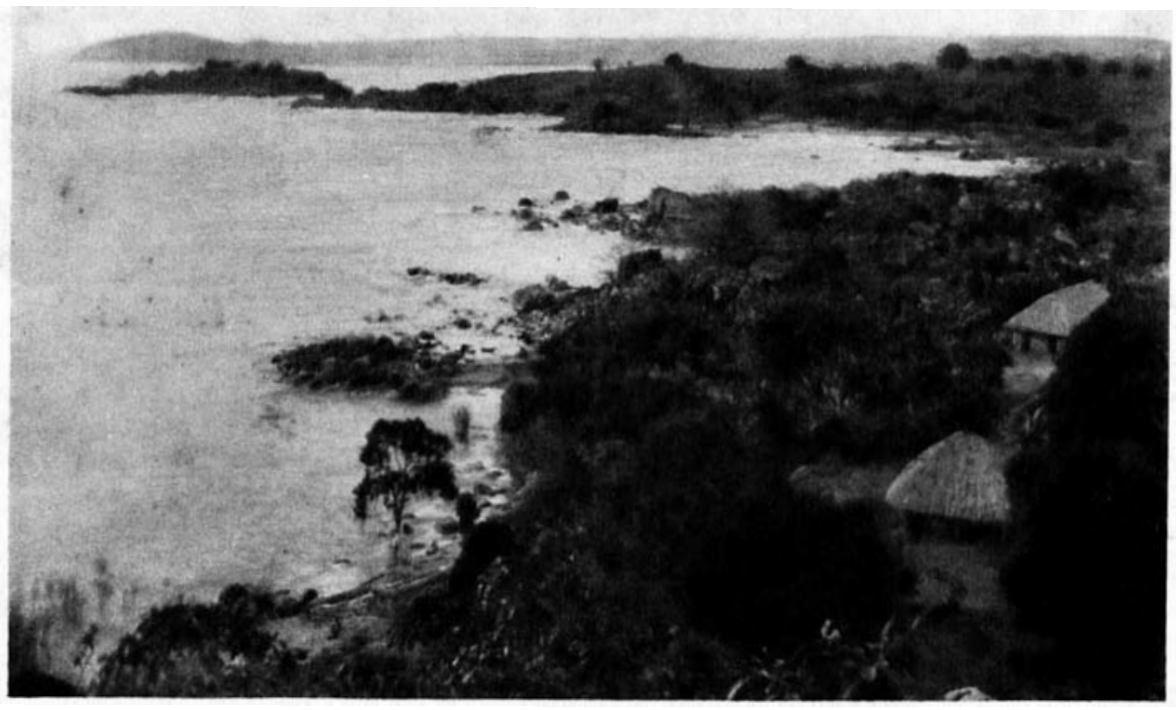

SHORES OH LAKE MYASA.

Ingehe in the distance.

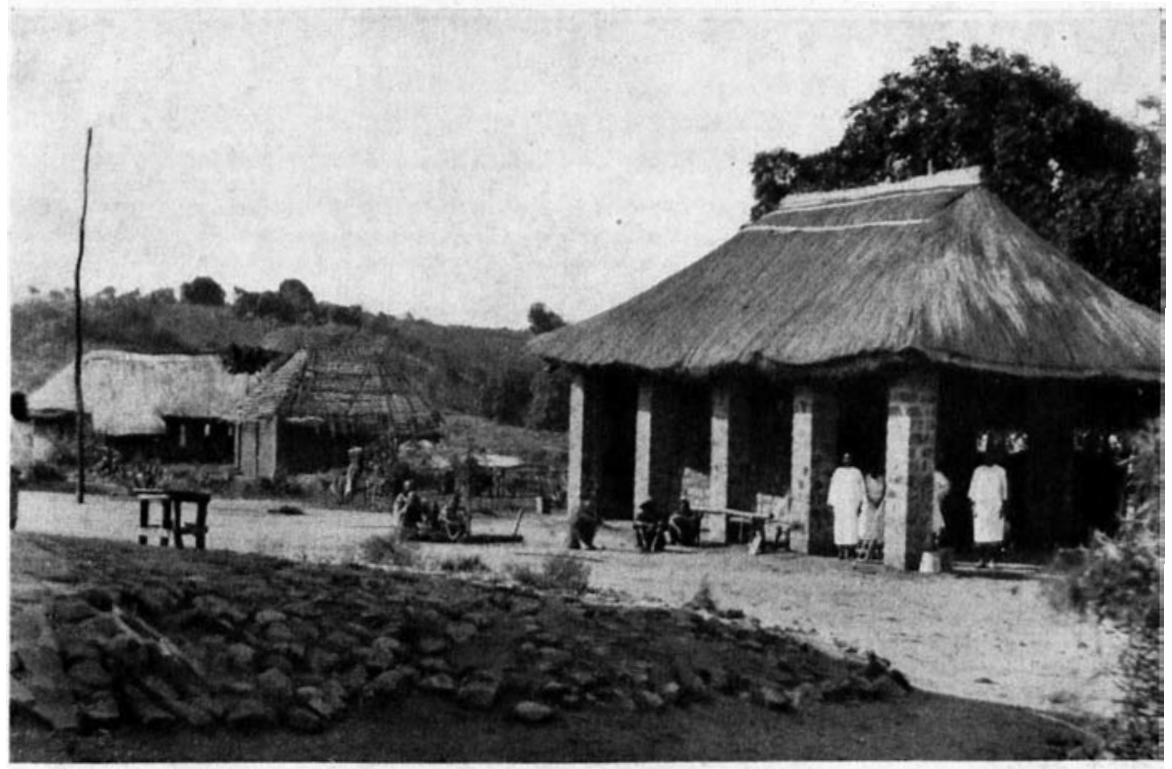

